\title{
El comercio de muebles en Cataluña durante el siglo XVIII ${ }^{1}$
}

\section{The furniture trade in Catalonia during the $18^{\text {th }}$ century}

\author{
Mónica Piera Miquel \\ Asociación para el Estudio del Mueble. Barcelona
}

\section{RESUMEN}

A partir de documentación de distinta índole conocemos los diferentes sistemas de venta y consumo utilizados en el comercio interno de muebles en Cataluña durante el siglo XVIII. Ofrecemos informaciones sobre la construcción de piezas y sobre su comercio desde los talleres de carpinteros, tanto de obras nuevas como de segunda mano y sus precios. Igualmente, estudiamos el importante negocio de muebles de alquiler ofrecido por carpinteros y por ropavejeros.

Palabras clave: Mueble, Carpinteros, Siglo XvIII, Sistemas de producción, Comercio, Cataluña, Consumo.

\section{SUMMARY}

Through various types of documentation it is possible to determine the different methods of sale and consumption used in the internal furniture trade in Catalonia during the $18^{\text {th }}$ century. The author offers information concerning the construction and commerce of pieces - new as well as second-hand ones- from the workshops of carpenters, and their prices. She also studies the major business of rentals offered by carpenters and secondhand dealers.

Key words: Furniture, $18^{\text {th }}$ Century, Trade, Catalonia, Consumption.

\footnotetext{
${ }^{1}$ Para la redacción de este artículo hemos utilizado información incluida en nuestra tesis doctoral "La 'calaixera' o cómoda catalana y sus variantes tipológicas en el siglo XVIII" presentada en la Universidad de Barcelona en 2002. No hubiéramos podido escribirlo sin la ayuda de Francesc Cirera, al que agradecemos su dedicada colaboración. Las siglas de los archivos citados corresponden a ADG, Archivo Diocesano de Gerona; AHCB, Archivo Histórico de la Ciudad de Barcelona; AHPB, Archivo Histórico de Protocolos de Barcelona.
} 
La información disponible, referente al comercio de mobiliario en Cataluña durante el siglo XVIII, es escasa y la obtenemos a partir de datos aislados recogidos en documentos de diferente procedencia que intentaremos aquí reunir y comentar. Comprobaremos que el siglo XVIII no aportó grandes novedades en los sistemas de venta de muebles, aunque la reactivación de la economía catalana en la segunda mitad de siglo acarreó un aumento del consumo, con su consecuente dinamismo comercial y el aumento de negocios dedicados a satisfacer la demanda de objetos para los interiores domésticos. Hemos centrado el interés en el comercio de muebles locales y en especial en el de la capital catalana, pero igualmente incluimos datos de otros centros, especialmente de las comarcas de Gerona, en concreto de Gerona capital, Olot, la Bisbal, Tossa de Mar y Torroella de Montgrí. Dejamos para otra ocasión, ya que sobrepasa el ámbito de este trabajo, el comercio exterior, que es sin duda de gran interés y merece ser estudiado minuciosamente.

\section{VENTA DESDE LAS CARPINTERÍAS}

\section{Muebles por encargo}

Los documentos nos informan de que el artesano que construía muebles tenía tres principales sistemas para comercializarlos: el encargo, el semiencargo y la venta directa. Cuando M. Paz Aguiló estudió el mobiliario de los siglos XVI y XVII en España citó la compra directa y los encargos desde los talleres artesanales como métodos habituales en su comercio (Aguiló 1993: 31); desveló que un buen número de muebles eran encargados directamente por los clientes al carpintero de confianza y que las más bellas piezas se adquirían a través de mercaderes. Por nuestra parte, al analizar varios talleres abiertos en Barcelona en el siglo XVII, pudimos conocer ejemplos como el de Lluís Massot, carpintero activo hasta 1608, con un volumen de negocio espectacular que utilizaba la subcontratación para poder satisfacer la alta demanda y construía muchas piezas de forma seriada para su venta directa desde el taller. Este artesano acumulaba las partes de los muebles más comerciales cortadas y preparadas para montar, que ensamblaba y acababa a medida que recibía encargos, mientras que el número de muebles totalmente listos que esperaban comprador era pequeño. Además de particulares, entre sus clientes contaba con negociantes que le ayudaban a dar salida a la producción. En aquel estudio observamos también que a finales de siglo XVII no se detectaban novedades en el comercio de muebles desde los talleres y que los carpinteros seguían utilizando los mismos mecanismos que a comienzos de siglo para vender los muebles que construían, aunque en 
ningún caso localizamos un obrador tan importante como el de Massot (Piera 2006b).

Ya en referencia al siglo XVIII, y en concreto a la venta de cómodas en Cataluña, Mainar afirma que el encargo es el sistema más común (Mainar 1989: 74) ${ }^{2}$. Efectivamente, la venta por encargo seguía siendo el procedimiento de adquisición de un gran número de muebles, sobre todo de calidad, ya que permitía que el cliente escogiera todos los detalles de las piezas. Desconocemos hasta qué punto el comprador se implicaba realmente en el proceso de producción, pero sí sabemos que el carpintero, sillero o el tallista aconsejaban al cliente acerca de sus trabajos, para lo cual se ayudaban de alguna traza o boceto y de piezas acabadas o a medio hacer que utilizaban de muestra.

Una parte de los principales muebles de las casas acomodadas se realizaron por encargo expreso del cliente. Si se deseaba un mueble con particularidades determinadas, ya fuera con materiales mejores de lo habitual, de medidas o formas especiales, o si se buscaba una pieza novedosa, espectacular o sorprendente, esa era la forma de llegar a conseguirla. Aquellos clientes que deseaban un mueble que todavía no estaba popularizado lo encargaban a su carpintero de confianza, a partir de algún modelo visto en el mismo país o en el extranjero.

La principal ocasión para el encargo de objetos de lujo eran los enlaces matrimoniales. No sólo los muebles que formaban parte de una dote eran de encargo, siempre que la economía familiar lo permitiera, sino que además el acondicionamiento que se emprendía en las viviendas con ocasión de las celebraciones y para alojar al nuevo matrimonio solía provocar reformas, modernización de las mismas y encargo de algunos muebles, principalmente la cama de la nueva pareja.

Documentos relativos al encargo de muebles son escasos en Cataluña. Normalmente, cuando un particular deseaba una pieza llegaba a un sencillo acuerdo, que podía ser oral o escrito, sobre sus detalles, su precio y el plazo de entrega, pero no solía acudir al notario para registrarlo. Lo dicho permite entender la dificultad para conseguir información escrita que docu-

2 "La seva confecció (de la calaixera) posava a prova l’habilitat i el bon gust del mestre ebenista que les construïa, quasi sempre, per encàrrec" dice Mainar. No nos parece apropiado denominar ebanista al artesano catalán anterior al siglo XIX que realiza muebles, como hace Mainar. La documentación muestra que los artesanos que realizan muebles hasta el siglo XVIII formaban parte del gremio de fusters, es decir de carpinteros, y no tenían una consideración específica. Sabemos que algunos de ellos trabajan realmente con chapas y utilizan maderas exóticas, pero en la época no recibían un tratamiento diferenciado. El término ebanista sólo lo hemos encontrado en referencia a artesanos carpinteros de fuera de Cataluña, o a partir del 1800. 
mente este sistema de venta. A medida que el carpintero trabajaba una pieza, detallaba el tiempo empleado y los gastos en su libro de cuentas. Luego entregaba una copia de estos apuntes al cliente, papel que servía de factura. En él se contabilizaban los jornales, junto al barniz o el acabado correspondiente, la cerradura, llave, bisagras u otros materiales que hubiera necesitado. Se facturaban incluso los clavos requeridos, la cola y el tiempo empleado en el trasporte, el mismo procedimiento que se utilizaba en trabajos de carpintería para la construcción pero, en el caso de los muebles, sin pasar por el notario. En muchos inventarios de carpinterías se registran libretas de cuentas y notas de pagos. En los libros de cuentas del taller de la familia Martí de Tossa que han llegado hasta nosotros (Moré 2000) quedan apuntados los gastos y jornales en la realización de armarios, mesas y otros muebles, y entre medio de las hojas de la libreta se conservan todavía algunos papeles sueltos que deben responder a las notas de gastos que el carpintero presentaba al cliente ${ }^{3}$.

Normalmente el comprador tenía que entregar un anticipo para que el carpintero iniciara el trabajo y para costear la compra del material, especialmente la madera. En estos casos, el maestro firmaba un recibo donde anotaba el precio total de la pieza, la cantidad cobrada y la fecha de entrega. El registro de una de estas pagas y señales lo conocemos por la denuncia que el herrero Jaime Sala interpuso contra Francesc Morató. El denunciante declaró que había adelantado 30 libras de las 40 que se habían estipulado por la construcción de un buró y una cómoda que debían ser entregados en el plazo de un mes y que el acusado no había cumplido lo pactado. El veguer dictaminó otorgar a Morató un plazo de 15 días para acabar los muebles bajo la pena de una multa de 25 libras. El carpintero reaccionó pronto y consiguió que un colega construyera los muebles por él, solventando así el asuntó ${ }^{4}$.

En casos de denuncia como el anterior, podemos localizar referencias relativas a la venta de muebles a particulares. Una información que procede de las situaciones irregulares, ya que aunque la mayoría de los encargos dejaban satisfechos a los clientes, el incumplimiento del contrato privado podía ocasionar incluso cárcel. Un ejemplo límite lo encontramos en la relación profesional que se estableció entre el noble afincado en Gerona, Josep Francisco de Caramany, y el ebanista francés avecindado en la ciudad, Antoine Seux. En 1803 firmaron un documento privado donde el segundo

${ }^{3}$ En estos libros de cuentas del taller de Tossa se apunta que en 1798 el taller Martí había "treballat per la calaxera de Nogueras, jornals so és 12 de meus y 2 del noy".

${ }^{4}$ AHCB, Arxiu del veguer i del corregidor. XXXVII-1177. Año 1776 (nº 83). 1776, abril, 30, Barcelona. 
se comprometía a acabar un gran mueble escritorio con librería que en aquel momento se encontraba en el taller de un ensamblador de apellido Saunier. El señor Caramany accedió a pagar por adelantado el trabajo que debía realizarse directamente en la casa del cliente e incluía el chapeado con diferentes maderas exóticas, además de los vidrios y metales. El artesano se retrasó más de dos años en el cumplimiento del contrato y el documento privado que habían firmado sirvió al noble para reclamar una y otra vez ante la ley y enviar al artesano a la cárcel. Se intentó que desde allá acabara la obra, para lo cual se le iba enviando todo el material necesario, hasta que cansado de problemas, en 1806, el señor Caramany consiguió rescindir el contrato y que la obra fuera terminada por otro carpintero de la ciudad.

Aunque la existencia de casas comerciales europeas dedicadas a la venta de mobiliario y de objetos relacionados con la decoración de interiores viene de siglos anteriores (Aguiló 1993: 31), su presencia aumentó en Cataluña a partir de la segunda mitad de siglo XVIII, a medida que crecían las transacciones comerciales y el interés por embellecer las casas. La de Jan[cko] Kruybick con sede en Barcelona, por ejemplo, sirvió los vidrios y espejos de la casa del señor Caramany en Gerona, incluidos los del atropellado mueble 5 . Por su parte, carpinteros locales emprendedores probaron fortuna entrando también en el mundo de los negocios, con el objetivo de mejorar su situación económica y pasando a considerarse negociantes en lugar de artesanos. Las biografías de los carpinteros muestran cómo algunos, sin dejar el oficio, dieron ese paso (Arranz 1991), como es el caso de los hermanos Llausàs. Esta familia de carpinteros de Barcelona, procedentes de Flaçà en el Gironés, fue mejorando su posición económica en la ciudad y en 1785 Pere y Agustí crearon una compañía dedicada a la venta de madera y, todavía más: ellos dos, junto al tercer hermano Feliu, carpintero y tallista, fundaron otra compañía, en este caso para la construcción de sillas ${ }^{6}$.

Siendo la cómoda y el buró tipologías que se pusieron de moda en la casa catalana a partir de 1730 , es razonable pensar que los clientes inquietos que las deseaban, las encargaban, sin embargo, las informaciones al respecto las hemos localizado a partir de fuentes indirectas. En el inventario post mortem datado en 1735 del militar Josep de Duran Mora, quien vivía en Barcelona en la calle Lladó, podemos leer la siguiente descripción:

Se troba en casa de Sebastià Aldebó, fuster, una calaixera nova a la ingles[s]a ab quatre calaixos grans y quatre calaixets petits, dins dita calaixera de fusta de noguer y alba nova ab dos manillas y escuts de llautó a quiscun de dits calaixos grans y

5 Archivo Patrimonial Caramany.

${ }^{6}$ AHPB, Not. Francisco Madriguera Galí, 1792(I), fol. 253v-258r. 1792, abril, 10, Barcelona. 
ab son pany en quiscun de dits calaixos y bomba $^{7}$ de dita cala[i]x[i]era y dos claus ço és la una per dits calaixos y la altre per dita calaixera. La qual de ord[r]e de dit senyor Joseph de Duran ha fet y treballat dit Sebastià Aldebó per adorno de la casa de dit senyor Duran ${ }^{8}$.

El buró para el señor de Duran fue construido por encargo - de ordre, dice el documento- - No sabemos cuándo se hizo el pedido, pero debió ser en el mismo año de 1735, porque los encargos de este tipo solían tardar un mes en ser entregados. Estamos hablando de una fecha en la cual la cómoda se estaba consolidando como nuevo contenedor de moda entre la nobleza y la burguesía comercial, pero en la que todavía no estaba suficientemente implantada como para que los talleres las tuvieran preparadas para su venta. En realidad, no hemos encontrado ningún inventario de carpintero catalán de esta década que tuviera cómodas acabadas o a medio hacer en el taller, y en cambio, sí tenían otros artículos de mayor demanda, como arcas, arquillas o sillas. Esto permite deducir que las primeras cómodas fueron, o bien realizadas por encargo del cliente, o bien procedían de importación, como así lo demuestran otros ejemplos. Sebastià Aldabó, el artesano al que se le encomendó realizar el mueble, nació en 1670 y pertenecía a un linaje de carpinteros y escultores de Barcelona activo desde la primera mitad de siglo XVII (Arranz 1991: 3). De Sebastià era conocida su labor en las obras del altar de Nostra Senyora del Roser del convento de Santa Catarina, junto al escultor de Manresa Josep Sunyer. Curiosamente este trabajo se le encargó el mismo año que el escritorio del señor Duran. Desconocemos otras de sus obras de carpintería, pero la coincidencia cronológica de estas dos muestra la falta de especialización y la capacidad de combinar tareas de distinta índole en el taller de Aldabó. Los materiales del buró fueron el álamo blanco y el nogal, siendo los tiradores en forma de anillas y los escudetes de cerradura de latón. Es decir que, aunque esta pieza era de encargo, estaba realizada con los materiales más frecuentes en las cómodas

${ }^{7}$ Debe querer decir tomba, es decir tapa del escritorio.

8 AHPB, Pau Mollar, Inv. et Auctionibus, 1722-1743, fol. s/n.1735, septiembre, 19, Barcelona. Queremos hacer notar que el notario denomina calaixera a la anglesa a este mueble que en realidad es un escritorio del tipo buró (escriptori, en catalán) y no es la única ocasión en que esto ocurre. Curiosamente, la parte del escritorio se cita como calaixera, mientras que los cajones de la cómoda se nombran bajo el término calaixos. Inglaterra, en concreto el puerto de Londres, ejerce una influencia que será determinante para el escriptori. Creemos que sus scrutoires - anglicismo del término escritoire, o más bien de escritorio, que se referencia desde finales del siglo XVII- actualmente conocidos como bureau, así como sus variantes, bureau bookcase y bureau cabinet, son muebles fundamentales en la configuración y evolución del escriptori y el escriptori amb canterano en Cataluña. 
catalanas. El mueble se componía de cuatro cajones largos y cuatro más estrechos dentro de la tapa del escritorio, distribución habitual, aunque no tan común como la que dividía la fila superior de los cajones grandes en dos pequeños. En resumen, nos encontramos con un buró de estructura y materiales que nos son familiares, pero con la particularidad de saber que se trata de un trabajo mandado hacer por el comprador.

La mayor parte de los encargos de muebles por parte de particulares registrados ante notario los tenemos, o bien porque el cliente encomienda la pieza o piezas a la vez que trabajos de construcción, reformas integrales de casas o renovaciones de estancias, o bien porque formaban parte de algún crédito o censal. En los libros de cuentas de don Salvador de Puig i Diern, recogidos cronológicamente desde el 21 de marzo de 1758, leemos que en el año 1770, entre otras partidas relacionadas con las obras de la casa de la plaza del Vi de Gerona, se anotaron unos pagos a Miquel Ros e Ignasi Albrador, artesanos que realizaron buena parte de la carpintería. Acordaron los precios antes de iniciar la obra, de tal manera que los múltiples y diversos trabajos que a lo largo de los años generó la reforma integral, se ajustaban a una tabla de precios redactada en 1765 cuando se inició su labor. Se detalla el pago de la cama principal, que era de escultura, para la cual el artesano tenía que utilizar la madera que le proporcionaba el cliente. Esta fórmula de servir el cliente la materia prima era común en las zonas rurales, donde las familias acomodadas, propietarias de bosques, se enorgullecían de suministrar la madera de los muebles principales de su vivienda. El señor Puig pagó 39 libras, 9 sueldos y 6 dineros por los trabajos de la cama. En el mismo año encargó la construcción de dos canapés por valor de 33 libras, 12 sueldos y 3 dineros y, aparte, compró —que no encargó- 24 sillas con asiento de paja por valor de 8 sueldos y 6 dineros cada una; piezas que estaban pensadas para decorar las salas de la planta principal de su magnífica residencia. Entre las partidas más caras cabe destacar la que corresponde a tres espejos, un juego de veinticuatro cornucopias y tres arañas, una de ellas, la más grande, destinada al gran salón. El total de este conjunto de objetos de vidrio y cristal ascendió a 623 libras y 15 sueldos, cantidad a la que se debían sumar los portes, las cajas para su traslado y los derechos, lo cual informa, además, de que llegaron de fuera de la ciudad?.

Contamos con muchas cartas de pago firmadas por carpinteros que cobran trabajos en obras de construcción, donde se indican los jornales y material empleados. En alguna de ellas se incluye el coste de los muebles

\footnotetext{
9 (1758 y ss) ADG 5.2. Casa Carles libro 31. Heretats $i$ possessions de la casa Puig de Torroella de Montgri: Inclou les despeses de la casa de Torroella i les de la compra i obres de la casa de Gerona.
} 
encargados simultáneamente. Este es el caso de la ápoca que el carpintero de Barcelona Salvador Mayol firmó en 1775 por las obras realizadas en casa del señor Ramón Constansó, notario de la ciudad, donde además de importantes reformas en la estructura de la vivienda, construyó las librerías de los estudis; es decir, del despacho, realizadas de tal manera que hacían las veces de tabiques ${ }^{10}$.

Por su parte, Joan Soler firmó carta de pago a favor de don Fèlix de Prats y Santos, barón de Serrahí. En el documento se contabilizan los trabajos de madera para las obras de su casa y también los muebles que se realizaron para decorar la vivienda entre 1777 y 1779, cobrados en 1781. Destaca la pareja de cómodas para guardar la ropa blanca del barón, piezas teñidas en color caoba y barnizadas que, con tiradores de latón, costaron 41 libras y 10 sueldos. Fijémonos que, en este caso, la pareja de cómodas era propiedad de un señor y fue él mismo quien las utilizó, lo que cuestiona la idea de que todas las parejas de cómodas procedan de dotes y sean propiedad de la mujer. También es interesante anotar que el acabado que se escogió para estas piezas de la década de 1770 es el barnizado y el color caoba. En el mismo momento, Félix de Prats encargó otras piezas teñidas en el mismo tono; en concreto, una pareja de cómodas rinconeras para colocar en los ángulos de la alcoba, que ascendieron a 17 libras y 10 sueldos, un armario por el que pagó 40 libras y 10 sueldos, que el documento especifica claramente que era para guardar indumentaria, cosa poco común en la época, y una mesa con las patas cabriolé, por 7 libras. Joan Soler también le construyó un archivo de álamo blanco por 35 libras y 15 sueldos y una librería con vidrios en su frente, realizada en madera de pino sin teñir, por valor de 30 libras. En el mismo taller se hicieron veinticuatro taburetes en nogal torneado que sumaron 5 libras, 12 sueldos y 6 dineros y se proveyeron las anillas de madera para las cortinas y las mamparas que servían de doble cerramiento a las puertas de la casa, compuestas, como era habitual, por un armazón de madera y forradas de tela ${ }^{11}$. La obra conocida más importante del taller de Joan Soler es la carpintería realizada para el Palacio Moja en la Rambla de Barcelona entre 1775 y 1790 por encargo de la propietaria, Maria Lluïsa Descatllar, marquesa de Cartellá de Moja y cuya factura ascendió a 27.730 libras, 12 sueldos y 9 dineros (Alcolea 1987). La carta de pago fue firmada por Joan Soler Planas y detalla la participación del padre en las obras; de

\footnotetext{
${ }^{10}$ AHPB, Not. Mariano Avellà, Man. 1775, fol. 97v-99r. La firma estampillada de este artesano la localizamos en su día en una cómoda que se conserva en el Museu Maricel de Sitges (Piera y Mestres 1999: 161).

${ }^{11}$ AHPB, Not. Jacint Sendil, Protocolum, diciembre 1781, fol. 19v-20v. 1781, diciembre, 21, Barcelona.
} 
ella se deduce la subcontratación de otros especialistas que se ocuparon de trabajos puntuales: los serradores, el escultor Gerona Mauri, que realizó seis cartelas de madera para las puertas exteriores, y el tornero al que, entre otras cosas, se le encomendaron botones para detrás de los porticotes, pomos para decorar los pilares de la camas, el torneado de los pies del mismo mueble, ruedecillas de boj para hacer correr las cortinas, una cruz para un cabecero y las poleas de bronce para bajar la cortina de la alcoba. Este mismo carpintero fue el responsable de servir "las pells vermellas empleadas per cobrir tot lo cintra del armari de la plata"12.

Otro mueble de encargo es la cómoda de sacristía de la misma casa Moja, pero en este caso construida por otro importante taller de la ciudad, el de los Casadevall. Se trataba de una cómoda de nogal y con los interiores de álamo, decorada con pilastras y los compartimentos necesarios para los ornamentos, y los cajones llevaban tiradores nuevamente de latón por un coste de 36 libras ${ }^{13}$.

Una interesante información la hemos obtenido gracias a que el pago se incluía en un censal. Nos referimos a que don Anton de Foxà i Mora mandó hacer a Josep Font una cómoda por 33 libras, un tocador por 10 libras y una cama por 17 libras, 7 sueldos y 6 dineros, todo para su hija Maria Bernarda con motivo de su ingreso en el monasterio de Sant Joan de Jerusalem de Barcelona ${ }^{14}$. Eran éstos los tres muebles necesarios para cualquier mujer de su nivel social, aunque ingresara en un monasterio. De las piezas, la cómoda fue la más cara, porque sin duda el tocador de una novicia no incluía las joyas y la plata que se podría encontrar en uno de novia, ni la cama se adornaría con los cortinajes y dorados de los mejores ejemplares.

La única carta de pago exclusivamente redactada por la fabricación de muebles y que, por tanto, consideramos excepcional, es la firmada en 1782 por Joan Llor de Olot a favor de Anton Pasqual, domiciliado en Ripoll, donde deja saldado el pago de la construcción de dos cómodas que formaron parte de la dote de su hija Josepa Eudalda cuando casó con Ignasi Vayreda. Sólo la excelente calidad de los muebles y su alto precio pueden hacer entender la decisión de redactar este recibo que no incluye ningún otro concepto más que las 123 libras y 10 sueldos que se pagó por ellas ${ }^{15}$.

\footnotetext{
${ }^{12}$ AHPB, Not. Grau Cassani, Man. 1792, fol. 152r-154r. 1792, noviembre, 12, Barcelona.

${ }_{13}$ AHPB, Not. Grau Cassani, Manuale 1792, fol. 150v-151v. 1792, noviembre, 12, Barcelona

${ }_{14}^{14}$ AHPB, Not. Gaietà Olzina Massana, Primus Manuale $7^{\circ}$ Instr. 1776, fol. 168v-169r. 1776, febrero, 14, Barcelona.

${ }^{15}$ AHCO, Not. Pau Casabona i Queralt, Man. 1782, fol. 109r. 1782, junio, 3, Olot.
} 
El hecho de que, en la segunda mitad de siglo XVIII, la cómoda fuera un mueble común en los talleres barceloneses no es óbice para que los clientes siguieran comprándola por encargo. Hemos comentado que las bodas eran buena ocasión para ello, especialmente en el caso de este contenedor, así como de los tocadores y las camas. El barón de Maldà explica cómo hizo construir las cómodas que formaron parte de la dote de su hija Maria Escolástica en el taller de Manuel Riera y comprobamos cómo él en persona controlaba el trabajo en 1798:

En una botiga molt gran, i portal tan gran como que de botiga de fusters no se'n veu a altres més alts i amples, en lo carrer del Carme, passat Betlem i carrer d'en Joglar, davant de casa d'un sastre, treballen, ab altres fadrins fusters i aprenents, en obres de calaixeres del primor del dia, dos minyons, fills de l'amo, lo més gran nomenat Manuel Riera, d’edat setze anys, i altre més petit nomenat Francis$\mathrm{co}$, que havien servit d'escolans dos o tres anys atràs en la iglésia de Betlem; i són galants minyons, quals me coneixen, alomenos Manuel Riera, de quan era escolà. I en dita botiga se treballa lo parell de calaixeres per casa Castellbell (Amat 1987, IV: 30).

Efectivamente, Manuel Riera regentaba uno de los más grandes y renombrados talleres de Barcelona. Era hijo del también carpintero Agustí, procedente de Moià. Manuel consiguió la maestría en 1770 y ejerció diferentes cargos en el gremio. Su trabajo ha sido conocido a partir de los escritos de Rafel de Amat, pero a su holgada situación económica contribuyó el hecho de haber entrado en negocios paralelos, como el de proveer nieve a la ciudad (Arranz 1991: 412).

Los muebles podían encargarse también a artesanos de fuera de la capital. De entrada sorprende constatar que, teniendo Barcelona tantos talleres abiertos, se recurriera a pueblos alejados para su construcción, pero en la Cataluña del siglo XVIII algunos centros consiguieron un prestigio que les permitió la comercialización de sus productos fuera de su entorno. En este sentido es interesante el caso del taller Quintà de Maçanet de Cabrenys, un pequeño pueblo en los Pirineos, ya de camino a Francia. Hemos localizado dos muebles sobre los cuales Salvador Quintà firma de su puño y letra y detalla el cliente al que van destinados, en los dos casos de Barcelona. El más antiguo es un buró datado en 1742, en cuya trasera el maestro indica que fue construido para Gerònim Alterachs, oficial primero del Archivo Real de Barcelona ${ }^{16}$, mueble construido en dos partes superpuestas, posiblemente para facilitar su traslado (Piera 2006a: 21-22). La segunda pieza es un armario guardarropa de 1751 que realizó para el médico Josep Fornés de la capital catalana. Nos son desconocidos los métodos de mercadear y las

${ }^{16}$ El artesano escribe Archivero Real, pero en realidad el cargo más alto que tuvo Alterachs en el archivo fue el de oficial primero. 
vías para llegar al público de Barcelona, pero las piezas citadas y el considerable número de muebles conocidos atribuibles a este taller permiten concluir que su estrategia comercial fue buena y beneficiosa para su negocio.

Cuando en 1805 la Junta de Comercio interrogó al gremio de carpinteros de Barcelona sobre el destino de las obras que fabricaban sus agremiados y su precio con el objetivo de mejorar la industria nacional, la respuesta fue verdaderamente imprecisa, como la de alguien a quien se le pregunta por un secreto profesional, sin embargo, el documento confirma que las obras de lujo se seguían realizando por encargo:

Y oida y ben entesa dita proposició nominal discrepante fos resolt que los prohoms del present Gremi, en cumpliment de la citada ordre, foran present a la Real Junta de Comers, que los individuos de est Gremi han fabricat en dits anys tota espècie de carpinteria y de evanista y en edificis de casa com en diferents cosas de comoditat y lujo, instruments de treballar las arts y, en fi, tot cuant se pot desitjar en dita art de carpinteria, podent tenir la vanaglòria que igualan ab lo estranger. Que no es fàcil espressar sos destinos, perque los que no quedan al pais, que són los que més ocupan als individuos, los de lujo, los que manan fabricarlos no espressan lo destino los donan. Tampoch és fàcil espressar los preus, perque a proporció de la solidez o lujo de la obra és son valor y que en assó se possan de accort lo fabricant y lo comprador y en fi esposian y manifestian tot lo demés que mirian convenient ${ }^{17}$.

A diferencia de los pedidos de particulares, los realizados por instituciones o entidades, como cofradías, iglesias, ayuntamientos, etc., han dejado gran constancia documental, ya que en estos casos se redactaba un contrato donde se especificaban todas las condiciones y se exigía al artesano que siguiera la traza presentada a la firma del documento. Así ocurre cuando las iglesias decidían construir o renovar las cajoneras de sacristía. Plazos, estructura, materiales, número de llaves o procedencia de las maderas son datos concienzudamente indicados. Todo se reflejaba por escrito, incluso si se deseaba contrafondos de cajones para que no entraran las ratas. El precio se acordaba en el contrato, quedando a cargo del artesano todos los gastos que pudieran derivarse de la fabricación. Esta condición se anotaba en términos como estos: "posant el fuster tots els recaptes, això és fusta, mans, claus, ferramenta, panys i tot lo que sigui menester". Los pagos solían efectuarse en tres plazos, el primero al inicio, el segundo a media obra y el último al término de la obra y una vez pasada la revisión. Un buen ejemplo es el contrato para la construcción de la cajonera de sacristía de la iglesia de la Mercè de Barcelona por el carpintero Josep Osset en $1687^{18}$, o

${ }^{17}$ AHCB, Gremial 37-7, fol. 75r-75v.

18 AHCB, Consell de Cent, serie XIII, vol. 68, año 1686-1688, fol. 190v-191v. 1687, octubre, 21, Barcelona. 
la de la Iglesia del Pino, encargada a Francisco Carreras en 1755 por valor de 307 libras $^{19}$.

\section{Muebles de semi-encargo}

Otro sistema de venta desde los talleres era el que podríamos llamar de semi-encargo. El carpintero disponía de muebles empezados a la espera de que fuera el comprador el que decidiera la técnica decorativa, las ornamentaciones o su acabado; opción que ofrecía muchas ventajas, tanto al comprador como al vendedor. Por un lado, el cliente podía satisfacer sus necesidades en un plazo de tiempo más corto que el de las piezas por encargo y, en cambio, tenía la posibilidad de escoger muchos detalles del mueble. Al carpintero este método le ayudaba a agilizar la venta de objetos de fuerte demanda y se evitaba invertir tiempo y material en aquellos que no sabía cuando vendería, por lo que era especialmente utilizado para muebles grandes como cómodas, burós o para piezas decoradas, como las camas pintadas, en momentos de venta segura.

Cuando Pau Andreu intentaba explicar desde Mataró en 1778 cómo eran las cómodas de moda, dejó claro que la "calaixera amb escambell" estaba anticuada y que por aquella fecha ya se hacían de sólo cuatro filas de cajones pero, en cambio, pormenorizó que se realizaban a gusto del comprador, que escogía entre el frontis movido o recto (Martí Coll 1967: 127):

No tinch ben present las calaxeras, pero seràn naturalment com las que es feian algun temps de tres calaxos grans y dos de xichs y sobre tres o quatre calaxons; ara se fa ab tres calaxos grans y los dos xichs, sens los calaxos de sobre y nobstant de ferlas massissas se fan ab entradas y eixidas al frente o llisas, conforme lo gust del comprador, pero sempre aparexen mes visibles ab torta y en punt a perfils si fa lo que si vol, suposat no parlam de fullola sinós noguera massisa.

Es posible que el tocador neoclásico con marquetería que Rafel de Amat vió al pasar por un taller de Barcelona en 1797 respondiera a una de estas obras de semi-encargo, ya que se había dejado la parte central de la decoración vacía y preparada para poner un escudo:

En la botiga de fusters, [...] s'ensenyava un tocadores, ab sos quatre petges prims i polidets, tot fusta, sens entrar-hi en sos vius colors - encarnat, blau, groc, etc.pinzell algun, sí tot unió de fustes d'estos colors, ab un com quadro al mig, ab figures, i un com escut per posar-hi armes; [...] fa veure clar l'adelantament de nostres artesans, fent honor a nostre nació catalana (Amat 1987-1996, III: 210).

${ }^{19}$ AHPB, Not. Joan Olzina Cabanes, Manuale 20 Instr. 1754-1755, fol. 43r-45v. 1755, enero, 16, Barcelona. 
Los obradores que ofrecían muebles, a menudo disponían de algunos prácticamente acabados, de los cuales el cliente elegía pequeños detalles, como la inscripción de la fecha, en el caso de armarios u otras piezas que la llevaban grabada o embutida, o la imagen del patrono de la casa, el escudo familiar u otras referencias personales que quisiera mostrar. La decoración llevada a cabo por doradores y pintores de muchas de las camas policromadas parece responder a este método de trabajo. Una serie de modelos se repiten una y otra vez, mostrando fondos decorativos iguales y encontrándose las diferencias únicamente en las representaciones en el interior de la cartela central, donde se presenta una imagen religiosa determinada o los santos escogidos por la familia. El trabajo más o menos seriado daría respuesta a la diferente mano observada entre el contorno y el interior de la cartela de los cabeceros. Creixell (1999: 282) plantea esta hipótesis que creemos acertada y que nos sirve de ejemplo de muebles de semiencargo. Cuando nos encontramos una descripción de cama de matrimonio con las imágenes de los patronos de la casa puede responder a una obra hecha por encargo o de semi-encargo, ya que los modelos se ofrecían indistintamente:

... i en la capçalera, pintada i jaspeada, quedaven, al mig, pintats, sant Francesc i santa Rosa de Lima, noms d'aquells marit i mòller (Amat 1987-1996, III:146).

Un trabajo que siempre se dejaba para cuando el mueble estuviera vendido era la colocación de los metales. En otros casos, el carpintero dejaba acabado su parte del trabajo a la espera de que otro artesano se lo llevara para terminarlo. Esto ocurría en piezas que debían pintarse o dorarse, como la cama de pie de gallo que Pau Esplugas tenía en el taller en 1770 a la espera, como detalla el documento, de que el dorador la pintara al óleo ${ }^{20}$.

\section{Venta directa desde el taller}

A medida que una tipología de mueble era demandada con continuidad los talleres la ofrecían acabada y a medio acabar en una cantidad superior a la de los encargos que pudieran tener. Estas piezas servían de reclamo de su trabajo y les permitía cerrar ventas de forma inmediata. Es verdad que el tamaño de los muebles no dejaba acumular muchos de los grandes, como cómodas, armarios o burós, a diferencia de los que ocupaban menos espacio, como braseros o sillas, pero no es menos cierto que los más activos carpinteros de Barcelona llegaron a tener siete, nueve, diez

\footnotetext{
${ }^{20}$ AHPB, Not. Carlos Carbonell, Primus Liber Inv. et Enc. 1760-1773, fol. 188r-190v. 1770, junio, 25, Barcelona.
} 
o incluso doce ejemplares de muebles voluminosos acabados. No nos debe extrañar que, entonces, algunos se vieran obligados a colocar parte de esta mercancía por las diferentes estancias de su vivienda. Para estas piezas, el artesano seguía aquellos diseños que estaban de moda e introducía pocos cambios en los modelos que sabía que se vendían bien. ¿Cómo entender, si no, las enormes similitudes de muchas de nuestras piezas de mobiliario? A la hora de construirlos, el carpintero no arriesgaba y repetía las características formales que resultaban exitosas. De todos los llegados hasta nuestros días, muy pocos ejemplares se salen de los modelos conocidos y aunque todas las piezas son distintas, las diferencias son de detalle.

En 1741 Bernardí Pruns tenía para vender tres cómodas nuevas, tipología que a partir de ese momento algunos talleres de Barcelona empezaron a tener acabada a disposición de los clientes. Su taller era grande con ocho bancos de trabajo y servía a miembros de la nobleza catalana que, cuando acudían al obrador, podían admirar ejemplares acabados de arcas, papeleras, escaleras o incluso armarios ${ }^{21}$. Por su parte, en 1758, Francisco Soler Campins tenía listas para vender siete cómodas chapeadas, tres camas de álamo blanco con patas esculpidas en nogal, tres camas de pie de gallo, cuatro sillas en nogal esculpidas y seis cornucopias con corladura. Además, en el obrador había a medio hacer una pareja y nada menos que diez frontales de cómodas, un armario y un buró, y es que en esas fechas la venta de estos muebles estaba prácticamente asegurada para esta importante carpintería barcelonesa ${ }^{22}$.

Cuando Joan Llausàs falleció en 1764, dejó en el taller una pareja de cómodas de nogal y un armario ya chapeados, ocho banquetas y tres sillas para tapizar y un buró a medio hacer ${ }^{23}$. En el inventario del escultor y carpintero Anton Compte Bofill en 1792 se encontraron diferentes trabajos para vender y entregar. Además de florones, sacras o urnas, se anotaron facistoles, candeleros, tamboretillos, soportes de peluca y cuatro camas a lo imperial con sus correspondientes cabeceros ${ }^{24}$. A final de siglo, el número de muebles disponibles en los talleres aumentó, paralelamente a la demanda. En 1799 a Salvador Cahís, con taller especializado en marquetería y chapeados

${ }^{21}$ AHPB, Not. Sever Pujol, Liber 3 Inv. 1737-1741, fol. 275r-276v.1741, agosto, 12, Barcelona.

${ }^{22}$ AHPB, Not. Joan Olzina Cabanes, Man. 3 Inv. 1756-1758, fol. 179r-187v. 1758, agosto, 10 - septiembre, 7, Barcelona.

${ }^{23}$ AHPB, Not. Ignasi Claramunt Gavarró, 1r. Man. Inv. 1747-1767, fol. 296r-300v. 1764, septiembre, 13, 16, Barcelona.

${ }^{24}$ AHPB, Not. Cayetano Olzina Massana, Man. 5ํInv. 1792, fol. 33r-38v. 1792, enero, 30-marzo, 2, Barcelona. 
en la misma plaza del Pi de Barcelona, se le contabilizaron doce cómodas, entre acabadas, ya chapeadas, o a medio hacer, además de un tocador ${ }^{25}$.

El carpintero era un artesano muy preocupado por la competencia que le pudiera venir de los productos extranjeros, así como por los límites del trabajo de artesanos de profesiones cercanas. Estaba siempre dispuesto a defender sus intereses y a pleitear contra ellos, justo antes de que se impusiera el libre comercio. Pero, en cambio, constatamos que los carpinteros no se mostraban muy imaginativos a la hora de buscar medios para publicitar y vender sus productos. A diferencia de otros profesionales, rara vez colocaban anuncios en la fachada del obrador para llamar la atención sobre su presencia ni solían disponer de escaparates para colocar muestras de los géneros que vendían. Comerciaban dentro de las tiendas-talleres y su única herramienta de seducción debía ser el olor a serrín, cera o barniz. En todo caso, dejaban la puerta abierta para que los transeúntes pudieran husmear y obras acabadas a la vista para que fueran admiradas antes de ser entregadas al cliente. Este fue el caso de las cómodas que encargó el barón de Maldá para la boda de su hija, y de las que estaba bien orgulloso:

\begin{abstract}
Llest enterament lo parell de calaixeres nuvials per casa Castellbell del treball primorós del fuster Manuel Riera, en lo carrer del Carme, que és qui les ha treballades, i del treball de daurador Jaume Eroles, en lo carrer d'en Petritxol, quedaven visibles en aquella gran botiga de dit Riera. I, en efecte, se poden comptar sobresalients a quantes s'han fetes en Barcelona, per lo primorós de sa escultura en muntats istriats, figures de mig bustos en sos cantons, figures com perles, tot dorat, ab los escuts y panys rodons de plata, sobredorats; i el color de dites calaixeres, sent tot de caoba, esta vermellenca, tirant a color de cirera, ben enllustrada i envernissada, a punt ja d'entregar-se (Amat 1987-1996, IV: 87).
\end{abstract}

Posiblemente, el carpintero pensara que la mejor publicidad era la del boca a boca, la del cliente satisfecho y la del trabajo bien hecho. Arranz nos ilustró sobre la preocupación que sentía la menestralía barcelonesa por su imagen profesional, su honradez y su reputación y es esta preocupación la que le motivaba a trabajar dignamente (Arranz 2001: 62). Procurar la satisfacción de sus clientes era para ellos la mejor manera de conseguir nuevos encargos y no parecían preocuparse por probar nuevas fórmulas para vender los productos. Incluso a final de siglo, cuando pagaban anuncios en el Diario de Barcelona, normalmente dirigían la venta a piezas concretas y no para hacer publicidad de su taller. Publicitaban un producto sin dejar constancia del nombre del taller o del carpintero y dando como única refe-

\footnotetext{
${ }^{25}$ AHPB, Not. Fèlix Veguer y Avella, Man. Inv. 1799, fol. 367r-370v.1799, septiembre, 3, Barcelona.
} 
rencia la localización del taller dentro de la ciudad. Anuncios como este son de redacción común:

El carpintero del cementerio de las Moreras de Santa Maria del Mar, dará razón de los mostradores de nogal y otros enseres de tienda que está para vender ${ }^{26}$.

La profesionalidad permite entender que muchos de los carpinteros fueran hombres de confianza, que mantenían los clientes durante largo tiempo, a los que les hacían no sólo los muebles necesarios, sino también otros trabajos de madera de la casa. Esta idea de carpintero de la familia, encargado de las mejoras de la casa y también de aquellos muebles u herramientas de madera necesarios, parece confirmarse entre los de clase social alta. Los señores tenían el taller de toda la vida, muchas veces del barrio, que hacía grandes y pequeños remiendos.

\section{Precios de muebles de nueva construcción}

En 1704 la tarifa de precios para gravar las importaciones detalla el coste estimado de varias tipologías de muebles que nos orientan sobre su valor en el mercado ${ }^{27}$. El documento estima una arquilla de carey con capilla y cornisa, de seis palmos, en 55 libras; una de ébano de cuatro palmos, en 16 libras y 10 sueldos, mientras que las de nogal grandes se valoraban en 20 libras. Por su parte, un arca de nogal se estimaba en 15 libras y una de pino en sólo 3 libras. Según los datos de que disponemos sobre precios en el mercado de Barcelona, los precios de esta tarifa parecen bajos, ya que, por ejemplo, en 1673 se pagan 178 libras y 15 sueldos por una pareja de arquillas de segunda mano decoradas en carey y bronce, aunque, como sucede a menudo con este tipo de documentación, nos faltan datos para poder establecer comparaciones claras ${ }^{28}$.

Desde la Edad Media, las camas eran los muebles más costosos de la casa, sobre todo si se enriquecían con doseles y cortinajes de bellos tejidos. También en 1673 se pagaron 330 libras por los damascos verdes, pasamanería y decoración en oro de una cama con dosel y cortinas. Estos tejidos eran mucho más caros que el trabajo de la madera, aunque ésta se dorara. Más de un siglo después, la carpintería de una cama con pilares y

${ }^{26}$ Diario de Barcelona, 1815, tomo 69, no 2 , p. 4.

${ }^{27}$ La tarifa de preus de les teles, y altres sorts de robes, y mercaderies, que entren en lo principat de Catalunya, y Comtats de Rosselló, y Cerdanya [...]. Transcrito el apéndice documental en Piera y Mestres (1999: 294).

${ }^{28}$ AHPB, Jacint Sescases, Primus Liber Inventariorum 1668-1680, doc. 52. 1673, noviembre, 28. Inventario y encantes de los bienes que fueron de Joan Guitart. 
cabecera en caoba, con decoración en talla y aplicaciones en latón podía costar 85 libras $^{29}$ y la pintura color caoba y el dorado de la cama y el cabecero del marqués de Moja ascendió a 45 libras, en este caso sin contar los trabajos de carpintería ${ }^{30}$. Naturalmente se podía adquirir una cama sin necesidad de este dispendio, ya que un sencillo lecho de peu de gall ${ }^{31}$, es decir de pata bifurcada, costaba 5 libras y 5 sueldos, y si se le incluía cabecero se podía llegar a pagar unas 7 libras y 6 sueldos $^{32}$.

Podemos ofrecer el precio aproximado del mueble rey del siglo XVIII, la cómoda. El número de contratos, ápocas o facturas referentes a muebles nuevos es escasa, pero suficiente para entender el esfuerzo que suponía su compra. En cambio, los capítulos matrimoniales no permiten conocer su precio, a pesar de que en algunos de ellos se cuantifique la dote. La razón es que en ellos se hace una valoración del ajuar en conjunto que incluye además de los muebles, los vestidos y las joyas, siendo entonces imposible deducir el coste de cada una de las partes. Cuando los contrayentes son de familia noble o pertenecen a la burguesía comercial, las dotes pueden llegar a 24.000 libras y el ajuar se puede componer de hasta tres cómodas donde colocar la ropa y joyas de la novia, que puede ascender a 6.000 libras, pero los documentos no especifican el precio de cada uno de los bienes del ajuar. A mediados de siglo, comprar una cómoda nueva de calidad media costaba entre 20 y 30 libras. Por esta cantidad, el armazón sería de álamo blanco, chopo u otra madera blanca e iría chapeada en nogal, dispondría de las correspondientes llaves y cerraduras, y sus tiradores y escudetes serían de latón. Este precio podría verse aumentado o rebajado, dependiendo de los materiales elegidos y la calidad del trabajo. En el caso de que la cómoda estuviera chapeada con alguna madera exótica, como palisandro o caoba y si, en lugar de latón, llevara los tiradores y escudetes de plata, el precio que se tendría que pagar sería más del doble, unas 65 libras.

En 1753, una pareja de cómodas de nogal nuevas costó 50 libras barcelonesas en el taller Lamarca de Olot $^{33}$. En 1776 se pagó por una cómoda 30

${ }^{29}$ La descripción de la cama se detalla con estas palabras: "dos llits ab pilans ab sas capsaleras y guarnició de talla, ferramenta estanyada, virollas als pilans de llautó y fusta de cahova envernissada, cent setanta lliras". (A.H.P.B., Francesc Madriguera Galí, Manuale (II) 1791, fol. 149v-150v. Apoca de Josep Monsech a favor de don Josep Manuel de Pascali).

${ }^{30}$ AHPB, Gerard Cassani, 16 Manuale Instr. 1791, fol. 113r-116r.

${ }^{31}$ Sobre el significado del término peu de gall consultar Piera; Mestres, (1999:104, 143 y 148).

32 Anexo I. Documentos. Apocas, actas de asiento, contratos y ventas. 1776, febrero, 14.

${ }_{33}$ Anexo I. Documentos. Apocas, actas de asiento, contratos y ventas. 1768, septiembre, 10 . 
libras y el mismo año por un buró y una cómoda de nogal, con metales de latón, se adeudaron 40 libras ${ }^{34}$.

La información más fidedigna referente al precio de una cómoda nos la ofrece un papel enganchado en el interior de una pieza que ha llegado hasta nosotros y se conserva en el Museu Rural de la Espluga de Francolí en la provincia de Tarragona. Se trata una calaixera amb escambell de cantos achaflanados y frente ligeramente serpentino, del típico modelo catalán en nogal con un sencillo trabajo de fileteado de boj. En el papel en cuestión el artesano dejó constancia de las penurias del momento y reveló el precio exacto de venta:

La i feta jo Jph Miquel de la Espluga de Francolí, juriol del any 1802, lo preu sens guarnimens 32 lliures, ne val 35 però com és any de misèria per tot arreu se agut sic de balafia lo blat [ant lo ata] a 45 pacetas.

En 1791 un arca nupcial costaba 8 libras y 5 sueldos, aunque no sabemos la madera, ni la estructura del mueble; una mesa de nogal 12 libras, una mesa pintada de amarillo 6 libras y cada silla poltrona desmontable en corazón de nogal, 8 libras ${ }^{35}$. El precio de los armarios de Gerona era muy superior a estas cantidades, porque también entraban más jornales en su construcción. El coste de un buen guardarropa, incluyendo jornales, madera, cerradura, llave, tiradores y el barniz, superaba las 81 libras, ya que solo los jornales para construir un armario ascendían a más de 51 libras $^{36}$. En 1791, se cobraron 104 libras por tres interesantes armarios desmontables, que posiblemente eran de madera blanca, dos de ellos decorados con flores en oro ${ }^{37}$.

Uno de los problemas que compartían todos los talleres era la demora en los cobros. En muchos inventarios post mortem de carpinteros, junto a los bienes del artesano, se detalla una lista de deudores, y en ciertos casos se explica que las deudas eran incobrables. Los carpinteros Lamarca tuvieron que esperar quince años para percibir el dinero de una cómoda y éste no fue un caso aislado ${ }^{38}$. Pagos con ocho, diez o doce años de retraso eran

${ }^{34}$ El documento utiliza el término "cobre", pero suponemos que se refiere al latón, porque cita "se acostumbran poner en semejantes halajas". Anexo I. Documentos. Requerimientos, denuncias, sanciones y otros documentos gremiales. 1776, abril, 30.

${ }^{35}$ AHPB, Not. Francesc Madriguera Galí, Manuale (II) 1791, fol. 149v-150v. Apoca de Josep Monsech a favor de don Josep Manuel de Pascali.

${ }^{36} \mathrm{El}$ precio de los armarios lo recogemos de los libros de cuentas del taller Martí en Tossa, conservados en el Arxiu Municipal de Tossa.

${ }^{37}$ A.H.P.B., Not. Francesc Madriguera Galí, Manuale (II) 1791, fol. 149v-150v.

${ }^{38}$ Anexo I. Documentos. Apocas, actas de asiento, contratos y ventas. 1768 , septiembre, 10 . 
generalizados. Los muebles y trabajos de carpintería que Josep Monsech cobró en 1791 se le habían encargado en 1783, teniendo él que adelantar el dinero a otros profesionales que colaboraron en las obras. Esta carga económica debía ser una de las principales razones de la escasa solvencia de los carpinteros y de verse obligados a menudo a pedir hipotecas y préstamos ${ }^{39}$.

A la dificultad de hacer efectivos los cobros, se añadían los gastos que se debían afrontar sin demora, especialmente los sueldos, las tasas gremiales y el material necesario para el trabajo. Este hecho explica la escasa acumulación de maderas de los talleres, la poca presencia de maderas exóticas, así como el retraso en la compra de los tiradores y escudetes hasta que las piezas no se hubieran vendido. Creemos no errar si decimos que la cantidad de maderas disponible en cada taller es uno de los datos que mejor refleja el volumen de negocio y la solvencia de cada maestro menestral. Esta información permite entender porqué, en los trabajos por encargo, el carpintero exigía un anticipo que le permitiera satisfacer, por lo menos, la compra del material y esta es además la razón de que muchos carpinteros buscaran fortuna con el comercio de estas materias primas.

\section{VENTAS ILEGALES}

Paralelamente a la venta de muebles desde las carpinterías, en la Cataluña del siglo XVIII existían otros modos para la adquisición de mobiliario. Uno era la compra clandestina en talleres de artesanos no agremiados en aquellas poblaciones donde los profesionales estaban regulados por este sistema.

Los agremiados al Gremi de Fusters de Barcelona eran las únicas personas que podían construir y vender muebles en la ciudad. En el transcurso del siglo XVIII, fueron cuantiosos los pleitos que confrontaron a este colectivo con otras corporaciones a causa de las delimitaciones de sus respectivos campos de trabajo. El gremio, necesitado de aportaciones económicas, sancionaba a todos aquellos artesanos ajenos que se extralimitaban en sus competencias: a los torneros porque construían y vendían sillas, a los carreteros por hacer coches y carrozas, a los quincalleros por vender almohadillas de costura y a los merceros por hacer muebles. Hasta la construcción de unos estantes y un tablero por parte de unos quincalleros fue suficiente para expedientarlos. Normalmente la multa ascendía a 10 libras, además de

\footnotetext{
39 Varios son los documentos que dan referencia de los problemas económicos de los carpinteros. Dos ejemplos referentes al primer cuarto de siglo XIX los comentamos en Piera y Mestres (1999: 217).
} 
confiscarse la pieza trabajada, ante lo cual muchos afectados preferían pagar un poco más si con ello conseguían mantener en su poder el mueble.

Consideramos interesante citar algún ejemplo de los muchos documentos referentes a estas ventas ilegales. En 1737 el gremio de carpinteros firmó una denuncia contra dos hermanos romanos, Domingo y Gerònim, cuyo apellido sólo sabemos que empieza por N, por construir dos burós (calaixeres a tall de escriptori, dice el documento). Por fuerza debían perjudicar estos romanos al gremio de carpinteros de Barcelona, pues tenían la experiencia de haber trabajado en una ciudad donde se construían magníficos escritorios en nogal, que podrían ser la envidia de cualquier carpintero barcelonés. Burdas excusas, como alegar que el nogal y el pino no ensamblan bien, eran utilizadas por los agremiados, para no reconocer el verdadero problema: La competencia de muebles importados y de artesanos extranjeros cualificados instalados en Barcelona podían reducir el volumen de negocio, así como mostrar la mejor calidad de sus productos. La respuesta del gremio fue la quema de los escritorios, tan radical como ineficaz (Piera y Mestres 1999: 153).

Las demandas de los forasteros se intensificaron a medida que avanzaba el siglo. Ellos pedían la liberalización del mercado o al menos la posibilidad de entrar en el gremio, pero los carpinteros barceloneses intentaron por todos los medios limitar su entrada. El proceso seguido por el carpintero francés Jean Boulier hasta conseguir ser admitido en la cofradía, es un referente del conflicto (Arranz 1991: 76-77).

En la segunda mitad de siglo se extremó la lucha contra el mercado ilegal, cuando aumentó la competencia y cuando era muy cuestionada la validez del sistema gremial. Personas ajenas al gremio construían y vendían muebles aprovechando el momento de debilidad de estas instituciones e intentando hacer negocios de cualquier tipo. La cofradía actuaba contra los mancebos carpinteros que trabajaban como si fueran maestros, como es el caso de Josep Rusiñol en 1757, quien utilizaba un pequeño obrador en los bajos de la Real Audiencia para construir cómodas que vendía por medio de uno de los alguaciles. Rusiñol declaró que trabajaba al servicio del maestro carpintero Joan Andalt y que, por ello, no contravenía ninguna ordenanza; pero el gremio, desoyendo sus explicaciones, confiscó la pieza y las herramientas y le sancionó con una multa de 10 libras. También se levantó acta al alguacil por haber favorecido la existencia del taller clandestino y por haber vendido una de las cómodas. Intentó buscar excusas y alegó que se había construido el mueble para él y que al no haber sido de su agrado decidió venderlo. En relación al taller, el alguacil argumentó que en realidad era regentado por un maestro carpintero. Donde se contradijeron las declaraciones entre el mancebo y el alguacil fue al intentar explicar quién 
era el maestro propietario del taller y consecuentemente se obligó al alguacil a pagar también una multa de 10 libras $^{40}$.

La misma multa se impuso a Blas de Paz en 1759 por vender unas librerías (canteranos, dice el documento) nuevas, pero él, como buen negociante que era, propuso pagar trece libras y quedarse con la mercancía. El gremio de carpinteros aceptó el acuerdo, cogió el dinero y marcó los muebles con "las marcas del gremio" a fin de "que pudiese hazer con ellos lo que le pareciesse" ${ }^{41}$. Por otro lado, en 1765 se sancionó al carpintero barcelonés Lluís Sagués por tener dos talleres abiertos, algo que también prohibían las ordenanzas. En realidad, Sagués tenía a cuatro oficiales trabajando por su cuenta en el taller de un tornero llamado Xuriach, desde donde le suministraban muebles ${ }^{42}$.

Estas denuncias son una prueba de las continuas tensiones entre los artesanos que intentaban ganarse la vida en Barcelona construyendo muebles y de la fuerte competencia en un momento en que el número de carpinterías había alcanzado los trescientas (Arranz 2001: 173). Se debía conseguir trabajo como fuera y aprovechar cualquier ocasión para vender. Muebles como cómodas, tocadores o burós estaban de moda a partir de 1730 y eran una segura e importante fuente de riqueza por la que valía la pena arriesgarse, aún infringiendo leyes.

\section{VENTA DE SEGUNDA MANO}

Un método muy común para adquirir muebles y todo tipo de objetos era la venta de segunda mano, tanto en talleres que ofrecían esta mercancía, como, sobre todo, en almonedas.

La venta de segunda mano desde las carpinterías la podemos deducir a partir de los diferentes muebles viejos o usados que se encontraban en muchas de las tiendas. Por ejemplo, en 1750 Pere Costa, que era un carpintero con taller pequeño en la calle Fusteria de Barcelona, guardaba además de unos interesantes muebles acabados o a medio hacer — diez y seis taburetes de estrado torneados, una docena de sillones torneados, dos mesas circulares a la inglesa de chopo, dos escritorios, una artesa y una mesa de tijera de pino-, otros que se adjetivaron como viejos, entre los que destacamos una pareja de arcas nupciales de nogal, dos papeleras y una

\footnotetext{
40 AHPB, Not. Jaume Tos Romà, 20 Man. Sive Protoc. diciembre 1756 - abril 1757, fol. $97 \mathrm{v}-99 \mathrm{r}$.

${ }^{41}$ AHPB, Not. Jaume Tos Roma, 22 Man. Sive Protoc. diciembre 1758-junio 1759, fol. $426 \mathrm{r}-426 \mathrm{v}$.

${ }^{42}$ AHCB., Concells del Gremi de Mestres Fusters, 37-6, fol. 46r-64v.
} 
mesa de álamo ${ }^{43}$. De esta manera, los carpinteros se erigían como comerciantes de muebles usados, negocio paralelo al de su fabricación. Es cierto que el desorden, la falta de espacio y la tendencia en la época a no tirar nada y reaprovechar muebles viejos llevaban a acumular trastos y a reutilizar algunas de las partes para la construcción de nuevos muebles. Pero una cosa son las piezas adjetivadas en los inventarios como inútiles y otra diferente las que se consideran usadas. Sabemos que entre estos muebles usados había arcas y arquillas vacías y que por consiguiente no formaban parte del material del taller, sino que parecen responder a muebles para la venta de segunda mano.

Aparte de los nuevos muebles — taburetes, mesas de juego, camas, cómodas- en 1810 el carpintero Jaume Martí ofrecía un buen conjunto de muebles viejos — braseros, camas, burós, cómodas, mesas, cuadros-. Su número hace pensar que también él se dedicaba al negocio de segunda mano, igual que la cantidad de hierro acumulado nos informa de que compaginaba el oficio de la madera con el propio del herrero. En el taller descubrimos hierro en bruto, otro para hacer fogones y clavos, bisagras, golfos, etc. Sólo de cerraduras para cajón de armario y de arcas se contaron ciento veinticinco ${ }^{44}$.

Excepcionalmente y ya en época tardía, los muebles de segunda mano se localizaban en talleres de otros profesionales, como los registrados en este anuncio:

En casa del cerrajero Ignacio Farriol, calle de la Lleona, núm 16, darán razón de una cómoda, vulgo calexera, quasi nueva, y con guarnición á la inglesa, que se divide en dos mitades, para la facilidad del transporte, teniendo cada una su caxon, parte de las quales sirven de mesas estando de asiento, y se dará á precio muy cómodo ${ }^{45}$.

Que el carpintero se convirtió en el intermediario entre particulares que deseaban vender y comprar muebles también queda documentado en los anuncios publicados en la prensa. Los muebles podían trasladarse a un taller o almacén del artesano o mantenerse en casa del vendedor, a donde acudirían los clientes con la intervención del carpintero. Manuel Riera publicitaba con estas palabras la venta de muebles de un particular en 1815:

Se repite el aviso de que el Sr. Manuel Riera, maestro carpintero, que vive en la calle del Carmen, informará del sugeto que quiere vender los muebles siguientes:

${ }^{43}$ AHPB, Not. Fèlix Avella, Liber 2 Inv. et Enc. 1741-1754, fol. 169r-173r. 1750, noviembre, 21, Barcelona.

${ }_{44}$ AHPB, Not. Francesc J., Elías Bosch, Inv. 9, 1789-1815, 13v-16r.1810, marzo, 27, Barcelona.

${ }^{45}$ Diario de Barcelona, 1802, 25: 99. 
una mesa muy elaborada, pintada y dorada, con su correspondiente piedra: según el gusto del día, propia para debajo de un espejo grande: un armario grande y bueno por el estilo de los de Gerona: y unos mapas también muy grandes y buenos, que contienen las quatro partes del mundo, con sus correspondientes guarniciones negras y doradas: el todo se arreglará a un precio equitativo ${ }^{46}$.

A partir de la documentación encontrada en los archivos notariales podemos conocer el importante movimiento de bienes que suponían las almonedas, así como, la clase de objetos que se vendían y sus precios. Los muebles formaban parte de las ventas y los compradores podían ser de toda clase y condición social, siendo el grupo de los menestrales uno de los más numerosos. Se ofrecían todo tipo de géneros y a menudo salían a la venta objetos prácticamente nuevos que suscitaban gran interés. Éste es el caso de la cómoda con seis cajones descrita como molt bona que se puso a la venta en la almoneda de los bienes de la señora Josepha Solà, mujer del dorador Gaspar Montagut en 1718, una fecha temprana para que esta tipología se vendiera de segunda mano. El mueble subió a 24 libras y fue la pieza más cara de la venta ${ }^{47}$. Los carpinteros se citan entre los profesionales que pujaban habitualmente en las ventas públicas comprando bienes de segunda mano y, en especial, muebles. Quizás adquirían los muebles para aprovechar la madera, también podía ser que los compraran a bajo precio para su venta como objeto de segunda mano o, finalmente, para su alquiler, que es otra de las actividades que ejercen, como ahora veremos. Fuera cual fuera su finalidad, el comercio con objetos usados justificaría las asiduas compras de los artesanos de la madera en las almonedas de las ciudades y pueblos.

En general, constatamos que cada profesión adquiría en las ventas públicas objetos propios de su oficio: los colchoneros, colchones y los vidrieros espejos y vidrios. Los carpinteros eran buenos clientes de muebles y objetos de madera, ya que restaurando o reconstruyendo estas piezas podían hacer negocio. La presencia de carpinteros es especialmente numerosa en los encantes de bienes de otros compañeros de profesión, atraídos por la oportunidad de aprovechar gran parte del material vendido. Por su parte, las almonedas de los bienes de personas acomodadas se convertían en todo un acontecimiento social, donde acudían no sólo ropavejeros y menestrales, sino también la nobleza. En los encantes de los bienes de Manuela de Cruilles, que tuvieron lugar en enero de 1798 fue la baronesa de Rocafort quien compró su buró por valor de 30 libras.

46 Diario de Barcelona 1815, 50: 256.

${ }^{47}$ AHPB, Not. Buenaventura Galí, Liber Secundus Inv. et Enc. 1713-1726, fol. 139r$140 \mathrm{v}$. 
Precios de muebles de segunda mano

Hemos podido conocer los precios de muebles de segunda mano a partir de los encantes que siguen a algunos inventarios post mortem. Normalmente, en estos documentos no se hace una descripción de los objetos, sólo se apunta el nombre del comprador, la pieza que se adquiere y el precio pagado por ella. Pero en ciertos casos, podemos conocer más datos del objeto si logramos identificarlo entre los que se describen en el inventario que antecede a los encantes. Otra fuente de información para conocer los precios de segunda mano son las estimaciones que se encargaban para valorar los bienes que una mujer viuda aportaba en dote a su nuevo matrimonio.

Los precios de los muebles usados pueden ser muy distintos incluso entre piezas de la misma tipología debido a sus particularidades, así como a su estado de conservación. Para entendernos, podríamos decir que la información obtenida de los encantes del siglo XVIII es parecida a la que podemos recoger actualmente de los catálogos de las casas de subastas, donde los precios son poco reveladores si no se mencionan las características particulares de cada lote. Sólo una muestra amplia con ejemplos que detallen estos datos puede servir de fuente de información. El hecho de que un objeto sea de segunda mano no parece que afecte siempre a su precio, ya que si procedía de una buena colección o la pieza era especial, estos factores incidían positivamente en su valor y eran más decisivos a la hora de tasarlos que el de ser un objeto usado. Teniendo en cuenta estas premisas, creemos interesante comentar el valor económico de algunos muebles de los que han trascendido sus características principales.

Hemos comentado la cómoda de segunda mano vendida en 1718 por valor de 24 libras, siendo el objeto más caro de una almoneda, similar al de un ejemplar de nueva construcción. Exactamente en el mismo precio se valoró la cómoda en nogal y con cinco cajones, que Anna Maria Bosch constituyó en dote en ocasión de su segundo matrimonio, en $1776^{48}$. Fue el único mueble que componía el ajuar, cuyo precio total fue de 246 libras y 15 sueldos.

En 1745, otra cómoda usada, en esta ocasión de cinco cajones y decorada con figuras de escultura, propiedad de un comerciante, se vendió en 28 libras. Esta estimación alta correspondía, sin duda, a una pieza de calidad. En el mismo documento se estimaba una arca genovesa por 4 libras y 10 sueldos, cuatro sillas de Marsella con respaldo tallado y asiento de fibra

\footnotetext{
${ }^{48}$ AHPB, Not. Magí Artigas, Primus Liber Inv. et Enc. 1765-1791, fol. 44v-47v. 1775, mayo, 16, Barcelona
} 
vegetal, 4 libras, una pareja de arquillas grandes con sus soportes, decoradas con vidrios pintados, casi con seguridad napolitanas, ya pasadas de moda a estas alturas de siglo, se estimaban juntas en 32 libras, y un bonito baulito de carey con decoraciones en plata e incluso cerradura y llave de este material, en 10 libras y 4 sueldos $^{49}$. En 1819 la pareja de cómodas que la señora doña María Asumpta de Baldrich y Arandes aportó en segundas nupcias al señor don Joan de Amat y Jovany se tasaron juntas en 60 libras, siendo los tiradores de latón, mientras que el tocador en forma de mesa con dos cajones pintado de color blanco y espejo con marco dorado que incluía adornos de talla se valoró en 30 libras $^{50}$.

La almoneda de los bienes de Bartomeu Minguell en 1762 debió ser un gran acontecimiento en Barcelona. Este rico comerciante era una persona culta, interesada por la física, en especial por la óptica y también por la música. Entre otras cosas, disponía de cámara oscura, caja óptica y varios instrumentos musicales, incluso un Stradivarius. De la venta de sus bienes nos interesan las 110 libras que se pagaron por la cómoda con librería (calaixera amb canterano), cuyo cuerpo inferior de cuatro cajones imitaba mármol y abría por anillas en latón, mientras que la librería, pintada de azul, llevaba puertas acristaladas y se remataba con copete tallado y dorado. El precio incluía la porcelana y otros objetos que se guardaban en su interior. En los mismos encantes, por una pareja de cómodas de nogal pagaron 47 libras $^{51}$. También destacada debía ser la pareja de cómodas en nogal que en 1774 aportó en dote Isabel Soler, procedente de su anterior matrimonio, ya que se valoraron juntas en nada menos que 70 libras, nuevamente el precio más alto de los encantes y más caras que muchas de las de nueva construcción ${ }^{52}$.

Otra de las ventas públicas de interés fue la ya comentada de la señora Manuela de Cruilles. Puso en el mercado abundante plata, como las tres docenas de fuentes que pesaban 751 onzas y se vendieron por 1.442 libras, e incluso, una berlina por 250 libras. Los muebles más caros adjudicados fueron dos cómodas de color rojo por 60 libras, un armario por 40 libras, el mismo precio que dos espejos grandes con marcos dorados y el buró, arriba citado, de 30 libras, una cama pintada de blanco con perfiles y dosel

49 AHPB, Jaume Tos Romà, Man. 8 Sive Protoc. 1745, fol. 359v-367r. 1745, agosto, 19, Barcelona

${ }^{50}$ AHPB, Not. Juan Bautista Maymó, Man. 1819, fol. 50v-55v.

${ }^{51}$ AHPB, Not. Sebastià Prats, Liber 6 Cap. 1762-1764, fol. 162r-202r y 409r-432v. 1762, diciembre, 17, Barcelona.

${ }^{5}$ AHPB, Joseph Serch y de Boquet, Man. 29, 1774, fol. 76v.1774, febrero, 24, Barcelona. 
por 25 libras y una silla paridera por 4 libras y 10 sueldos. Las otras cómodas de esta almoneda se aproximaron a las 20 libras, un precio que ya hemos visto que se puede considerar medio entre las de primera mano ${ }^{53}$.

Entre las piezas caras de segunda mano, subrayamos una pareja de cómodas que había pertenecido al noble Francisco Xavier de Blanes Centellas y Carros, conde de Centellas, por la que se pagaron 122 libras y 10 sueldos en la almoneda de sus bienes en 1799. Aunque la documentación no informa de sus materiales, deducimos que se trataba de la pareja con metales de plata, mencionada en su inventario. En la misma venta las tapicerías del estrado, dormitorio y alcoba subieron a 243 libras, la librería, 22 libras y las dos docenas de sillas holandesas, casi 50 libras $^{54}$.

El precio acostumbrado para una cómoda de nogal sencilla de segunda mano estaría en torno a las 9 libras, aunque las había también de 16; mientras que las más baratas, construidas en pino pintado de blanco, podían costar tan sólo 4 libras y 10 sueldos. El precio de los burós era, en igualdad de condiciones, superior al de las cómodas. Cuando en 1785 se valoró una calaixera amb escambell, chapeada en nogal en 24 libras, un buró también chapeado en nogal con sus metales se estimaba en 32 libras y un espejo grande y cuatro cornucopias en 20 libras $^{55}$.

Si comparamos estos precios con los de las arcas, podemos entender que una de las razones de la lenta entrada de la cómoda y sus derivados en algunos estamentos sociales era, en parte, una cuestión económica. Pensemos que una pareja de arcas de nogal decorada en pinyonet, es decir con embutido de hueso y boj, costaba 25 libras y una pareja de arcas, también en nogal, pero sin decorar 11 libras, 12 sueldos y 6 dineros en el mercado de segunda mano. Si el arca era de álamo blanco su precio podía quedar en algo más de 2 libras. Viendo estos precios, podemos comprender porqué, en capítulos matrimoniales entre familias de nivel económico medio, el padre de la novia ofrecía a su hija la opción de escoger entre una cómoda o una pareja de arcas (Piera 2005: 265).

\footnotetext{
53 AHPB, Not. Francesc Joan Elías Bosch, Man. 26 Inv. 1788-1803, fol. 1r-19r. 1798, enero, 13- 27, Barcelona.

${ }^{54}$ AHPB, Josep Ribes y Granés, Prot. Inv. 1798-1803, fol. 37r-47v. 1799, enero, 2, 24, 29, Barcelona.

55 AHPB, Josep Ponsico, Pactis et Aliis, 1784-1787, fol. 97r-99v. 1785, enero, 9, Barcelona.
} 


\section{ALQUILER DE MUEBLES}

Por último, era posible alquilar los muebles, en lugar de comprarlos. Aguiló ya habló de este negocio en el Madrid del siglo XVII, en aquella ocasión regentado por un dorador (Aguiló 1993: 31). En la Barcelona del siglo XVIII, el aumento del número de forasteros que acudían por temporadas más o menos cortas a la ciudad, fue el motivo principal para la apertura de negocios dedicados al alquiler de todo tipo de bienes, pero en especial de muebles, ropa de la casa, disfraces, ropa personal y de trabajo. Cuando se quedaban pocos días en la ciudad podían alojarse en una posada, pero si su estancia era más prolongada solían buscar casa, algo que no era nada fácil, para lo cual necesitarían alquilar muebles. Imprescindible era la cama con toda su ropa, pero también se podía necesitar vestir la casa con brasero, mesas, sillas, espejos o consolas. Otros se alojaban en casa de algún familiar o conocido, debiendo en muchos casos alquilar la cama o al menos el colchón, la sábana y la almohada. El alquiler de muebles también era un recurso utilizado ante la celebración de una fiesta o cualquier acontecimiento social, destacando las bodas por la cantidad de muebles que se demandaban para tal ocasión. Vistos los altos precios de los muebles de primera mano es fácil darse cuenta de que el alquiler era para muchos un buen recurso.

En 1774 el comerciante Martí Creus y el colchonero Francesc Ventura abrieron una compañía para la venta de tejidos y el alquiler de ropas y muebles. Dos años más tarde redactaron un inventario para comprobar el estado de cuentas. En él se detallan todos los bienes, los deudores y las personas que en aquel momento tenían alquilado alguno de los objetos de la compañía. El listado permite apreciar la importancia del negocio que hacía necesario un almacén, aparte de la tienda para guardar la mercancía. La tienda estaba ubicada en Les Voltes dels Encants, lo que les permitía estar informados de todo objeto que se vendiera en los encantes de interés para su negocio. El número de colchones y de ropa de cama con el que contaban era muy elevado, pero también alquilaban ropa personal y muebles. Se citan nada menos que treinta y dos cornucopias y espejos, además de mesas, canapés, sillas, braseros y burós, todo para su alquiler. Disponían de camas de bancales grandes y pequeñas y alguna era pintada. Los clientes eran numerosos y de distinta procedencia. Los que adquirían lana u otras ropas eran en su mayoría colchoneros y sastres de Barcelona o procedentes de poblaciones como Arenys, Mataró, Calaf o Vilafranca. Entre los deudores de piezas alquiladas se cita al noble Francesc de Copons, aunque mayoritariamente eran extranjeros, cargos públicos y sobre todo, militares. 
Un ejemplo de este activo negocio es el listado de objetos alquilados el 25 de septiembre de 1776 a unos franceses que vivían en el primer piso del edificio de Martí Creus:

Un llit gran compost de dos banchs, quatre pots, quatre matalasos, dos llansols, dos coxins, dos coxineras, una colxa, un cobrillit de indianas, dos llits petits compostos de quatre banchs, sis pots, dos màrfegas, dos matalassos, quatre llansols, dos coxins, dos coxineras, dos flassadas, la una vermella, y la altre grisa, trenta y tres cadiras, dos taulas de petges forts, y una de rodona, un ganapé ab matalàs, dos coxins, unas cortinas de indianas novas, vuit cornocòpias ab figuras, arrimaderos de indianas nous, un mirall, un quadro de Nostra Senyora de la Mercè, una calaxera, un canterano y un tapete de indianas nou, una cortina blanca per lo balcó y dos barretas ${ }^{56}$.

Otra tienda dedicada a la venta y alquiler, todavía con más actividad que la anterior, era regentada por el ropavejero Joan Guix. Su inventario post mortem, datado en 1799, nos demuestra el volumen de su negocio, nuevamente situado junto a los Encantes de Barcelona. Los diferentes bienes los disponía por distintas estancias de la casa, pero además era propietario de almacenes con un número importantísimo de trajes, disfraces, toallas, colchones, almohadas, sábanas y muebles. Los cubrecamas para las camas de alquiler los guardaba en un armario específico y otro lo utilizaba para los vestits de màscara. El documento cita ocho cómodas y burós que estaban alquilados en ese momento. Si contamos los bienes repartidos entre la tienda, el almacén y las casas de los diferentes clientes, sumaban cincuenta mesas, cuarenta cornucopias, veintitrés docenas de sillas, además de biombos, mesas de juego, braseros, armarios, alfombras. También tenía ropa para vender, parte nueva y parte de segunda mano, alguna de gran calidad en terciopelo con bordados en plata, y se contabilizan muchos uniformes de guardia y de miguelete ${ }^{57}$.

Algunos carpinteros entraron en este negocio de alquiler de muebles. Para ellos resultaba fácil incluir entre las tareas del taller la construcción de unas cuantas piezas sencillas o su compra en mercados públicos para ser alquiladas. Tenemos constancia del alquiler de camas, pero, como comentábamos anteriormente, quizá algunos de los otros muebles inventariados en las carpinterías podían servir también para ser alquilados. Josep Llunell era uno de los carpinteros de Barcelona que se había adentrado en este negocio. Cuando falleció, en 1774, en el taller de la calle Portadores se encon-

56 AHPB, Not. J. Fco. Claramunt Cardeñes, Man. 20 Prot. 1776, fol. 209r-226r. 1776, noviembre, 5, 6, 10, Barcelona.

57 AHPB, Not. Joseph Ribes y Granés, Prot. Inv. 1798-1803, fol. 11r-16r.1799, enero, 10, Barcelona. 
tró el libro de registro de las camas de alquiler, dos libros de cuentas y diversos papeles que mostraban que su clientela incluía personas de origen francés. Almacenaba colchones, mantas, catres, una silla de campaña para niños, sillas poltronas, sillas pintadas y con asiento de enea y mesas, todo ello además de los muebles nuevos para su venta ${ }^{58}$.

El alquiler se convirtió, así, en otro recurso comercial de los carpinteros, que aunque en la mayoría de los casos no abandonaron el trabajo artesanal, intentaron con ello dinamizar la actividad de sus talleres. Fue un mecanismo más de los utilizados por los artesanos para luchar contra la dura competencia y para dar respuesta a las necesidades de una clientela dispar, propia de un contexto de alta actividad económica y comercial. El consumo de bienes de uso doméstico se llevaba a cabo por diversas vías, siendo la pieza de encargo y la compra de muebles nuevos sólo una opción más entre las diversas posibles. El alquiler y la compra de segunda mano jugaban en el mercado del mueble catalán un papel fundamental que permitía que una buena parte de la población accediera a aquellos bienes de consumo deseados.

\section{BiBLIOGRAFÍA CITADA}

Aguiló, M. P. 1993. El mueble en España Siglo XVI y XVII. Madrid: CSIC y Ed. Antiqvaria. Alcolea, S. 1987. El Palau Moja. Barcelona: Generalitat de Catalunya.

Amat, R. 1987-1996. Calaix de Sastre. Barcelona: Curial. Edición a cargo de R. Boixareu. Arranz, M. 1991. Mestres d'obres i fusters. La construcció a Barcelona en el segle XVIII. Barcelona: Col.legi d’Aparelladors i Arquitectes Técnics de Barcelona.

Arranz, M. 2001. La Menestralia de Barcelona al segle XVIII. Els gremis de la construcció. Barcelona: Proa.

Creixell, R. 1999. "Els llits policromats. Revisió de la tipologia 'd'Olot'”. Annals Patronat d'Estudis Històrics d'Olot i Comarca: 271-291.

Mainar, J. 1989. Vuit segles de moble català. Barcelona: Rafael Dalmau.

Marti Coll, A. 1967. Cartes d'un mestre veler, 1770-1794. Mataró: Caixa d'Estalvis de Mataró.

Moré, D. 2000. Cas Fuster: La família Martí a través dels seus documents. Tossa de Mar: Quaderns d'Estudis Tossencs.

Piera, M. 2005."La cómoda y el tocador, muebles de prestigio en la sociedad catalana del siglo XVIII". Pedralbes 25: 259-282.

Piera, M. 2006a. "El moble de l'Empordà al segle XVIII", en El moble de l'Empordà al segle XVIII: 7-25. Gerona: Fundació Caixa de Gerona.

Piera, M. 2006b. "El mueble en la documentación de Barcelona en el siglo XVII. El inventario y la almoneda de los bienes del carpintero Lluís Massot de 1608 y el inven-

${ }^{58}$ AHPB, Not. Carlos Carbonell, Manuale 2 Inv. et Enc. 1774-1779, fol. 5v-11v. 1774, marzo, 9, Barcelona. 
tario de Joan Francesc Pratnarbona de 1688", en El moble del segle XVII a Catalunya i la seva relació amb altres centres europeus: 69-82. Barcelona: Associació per l'Estudi del Moble.

Piera, M y A. Mestres 1999. El mueble en Cataluña. El espacio doméstico del gótico al modernismo. Manresa: Angle.

Fecha de recepción: 19 de diciembre de 2007

Fecha de aceptación: 20 de enero de 2008 